\title{
Do Firm Cues Impact Product Perceptions? When Small is Natural
}

\author{
Ana Scekic \\ Erasmus University Rotterdam
}

\author{
Aradhna Krishna iD \\ University of Michigan
}

Accepted by Priya Raghubir, Editor; Associate Editors, Manoj Thomas and Cornelia Pechmann

\begin{abstract}
Firms of varying size can produce the same product. Do consumers make inferences about products based on firm size? We focus on perceptions of product naturalness and show, in four studies, that products made by smaller firms are perceived to be more natural - whether they are directly experienced (study 1) or seen in ads (study 2). Additionally, we show that the association of firm size and naturalness is held nonconsciously (study 3), and also consciously (study 2); and that it impacts purchase intention (studies 2 and 4). Our research has many implications for firms conveying product naturalness. Importantly, it highlights the need to explore possible associations between firm characteristics and product perceptions.
\end{abstract}

Keywords Firm cues; Firm size; Product naturalness; Product perceptions

Firm size varies a lot, with small firms earning low revenues, having few employees and selling their products in a handful of stores; and large conglomerates making millions of dollars each year, having hundreds of employees and selling in stores across the world. Yet, both types of firms can produce the same product: a simple family-business or a large multinational firm can both produce lip balm or chamomile tea. Can firm size affect consumer perceptions of the product? If it can, firms should heed this association as they grow larger in size. We show that consumers do use firm size as a cue for product attributes, which can impact consumers' purchase intention.

The product attribute we focus on is naturalness - an attribute important for many reasons. A 2016 Nielsen survey showed that consumers increasingly prefer products with more natural ingredients (https://www.nielsen.com/au/en/insights/article/ 2016/serving-up-simple-global-consumers-want-tra nsparency-in-ingredients/). Prior research on naturalness has studied what product cues can prompt naturalness (e.g., packaging elements; Labbe, Pineau, \& Martin, 2013), but has not looked at firm-

Received 19 December 2018; accepted 23 November 2020 Available online 03 December 2020

Authors are listed in reverse alphabetic order. Both authors contributed equally to the research.

This work was started while the first author was visiting Professor Krishna's Sensory Marketing Lab at the University of Michigan.

Correspondence concerning this article should be addressed to Ana Scekic, Erasmus School of Economics, Erasmus University Rotterdam, P.O. Box 1738, 3000 DR Rotterdam, The Netherlands and Aradhna Krishna Stephen M. Ross School of Business, University of Michigan, 701 Tappan St., Ann Arbor, MI 481091234, USA. Electronic mail may be sent to scekic@ese.eur.nl and aradhna@umich.edu. based cues. In fact, while much research has connected product cues with product perceptions, little research has investigated the relationship between firm cues and product perceptions. We build on the existing research on naturalness (e.g., Rozin, 2005), and suggest that there exists a "smaller firm $=$ more natural product" intuition.

We demonstrate the association of firm size and product naturalness in four studies, across different contexts, so that products from smaller firms are perceived to be more natural. We show that the size-naturalness association is deeply ingrained so that it can be held both consciously (i.e., one can be aware of the belief) and nonconsciously; and that the association then impacts purchase intention. Our results point to the existence of competing mediators of firm size effect on purchase intention and invite further research to identify them.

\section{Prior Literature and Conceptual Development}

Let us first understand what "naturalness" is. The Cambridge dictionary defines natural "as found in nature and not involving anything made or done by people." This is consistent with Rozin et al.'s (2004) suggestion that human intervention (e.g., processing) contaminates natural entities and deprives them of their essence. Rozin (2005) argued

(C) 2020 The Authors

Journal of Consumer Psychology published by Wiley Periodicals LLC on behalf of Society for Consumer Psychology

This is an open access article under the terms of the Creative Commons Attribution License, which permits use, distribution and reproduction in any medium, provided the original work is properly cited. 1057-7408/2020/1532-7663

DOI: $10.1002 /$ jcpy. 1210 
that mixing a natural entity with another entity (natural or not) reduced perceived naturalness. This "contagion principle" (Rozin \& Nemeroff, 1990) is, to a great extent, responsible for the perception of the loss of naturalness.

One could argue, therefore, that living organisms are closest to their completely pure and natural form when they are "born" (i.e., when they are small); since as they grow, they are more likely to change and be "contaminated" by the environment, and by contact with other entities. This would also hold true for firms: as firms grow, they have more time, and a larger size, for contamination possibilities. Supporting this reasoning further is research by Smith, Newman, and Dhar (2015) on temporal contagion, showing that consumers prefer products with earlier (vs. later) serial numbers, as they are perceived as "closer to the origin," and containing more of its essence.

Thus, small entities are perceived as being closer to their own natural essence-present at their "birth" - and therefore more natural than more "grown up" entities. We propose that smaller firms are perceived as more natural, and that this perception spills over to a "smaller firm = more natural product" intuition. This intuition may also stem from beliefs that larger firms have more automation and machinery (e.g., Swamidass \& Kotha, 1998), leading to more processing of materials; and also that mass production requires the use of cheaper, less natural, materials. We further suggest that the "smaller firm $=$ more natural product" intuition is scaffolded on an implicit association of the broader concepts of size and naturalness (i.e., "small = natural").

The association we propose adds to a growing literature on automatic implicit associations between specific concepts, which allow consumers to rely on certain product attributes to make inferences regarding other, missing product attributes (Broniarczyk \& Alba, 1994). For example, consumers associate "healthy" with "not tasty" (Raghunathan, Naylor, \& Hoyer, 2006) and with "expensive" (Haws, Reczek, \& Sample, 2016). It also adds to conceptual metaphor theory whereby abstract concepts (e.g., naturalness) are understood by scaffolding onto concrete ones (e.g., size; Lakoff \& Johnson, 1980). In this vein, "naturalness" of food has been associated with rough (vs. smooth), supple (vs. rigid; Labbe et al., 2013), and matte (vs. glossy) packaging (Marckhgott \& Kamleitner, 2019). But, all these associations relate to product cues and not firm cues, which we study.

We test for our proposed small-natural association and its downstream effects in four studies.
Demographic and control variables are reported in the Methodological Details Appendix (MDA) and are discussed in the paper only in the case of meaningful interactions with the firm size effect on naturalness. The MDA also contains three additional studies.

\section{Study 1}

In study 1, participants perceptually experienced (i.e., touched) the product (towels), and we investigated the association of firm size and product naturalness.

\section{Method}

One hundred and eighty-two undergraduate students $\left(52.20 \%\right.$ females, $\left.M_{\text {age }}=20.69\right)$ completed the study in the behavioral laboratory of a mid-Western business school for course credit. The study had a 2 (firm size: small vs. large) $\times 2$ (salience of association: high vs. low) between-subject design.

Participants were told they would be shown a set of towels and asked some questions. In the high salience condition, the task instructions had one additional sentence: "We are interested in studying if the size of the company affects how natural you think the product is"; this sentence did not occur in the low salience condition. Participants were next shown a picture and a description of a set of towels. In the small firm size condition, the description read: "These towels were produced by a small company of 20 employees. They are made of a combination of organically grown cotton and conventionally grown cotton. Price of the towel set: $\$ 45 . "$ In the large firm size condition, "small company of 20 employees" was substituted by "large company of 20000 employees."

In addition to the product picture and description, each participant was given an envelope containing a swatch sample of the towels. The samples were cut out from a large white towel and were the same across all conditions (Figure 1).

To measure perceived naturalness, we asked participants to indicate the percentage of organic and conventionally grown cotton they believed the towels contained, using a 2-item constant sum bar scale (details in MDA).

As a manipulation check of "natural," we asked participants to indicate how natural they thought organic and conventionally grown cotton were (7-point scale; $1=$ "Not at all natural," $7=$ "Extremely natural"). A paired sample $\mathrm{t}$ test 

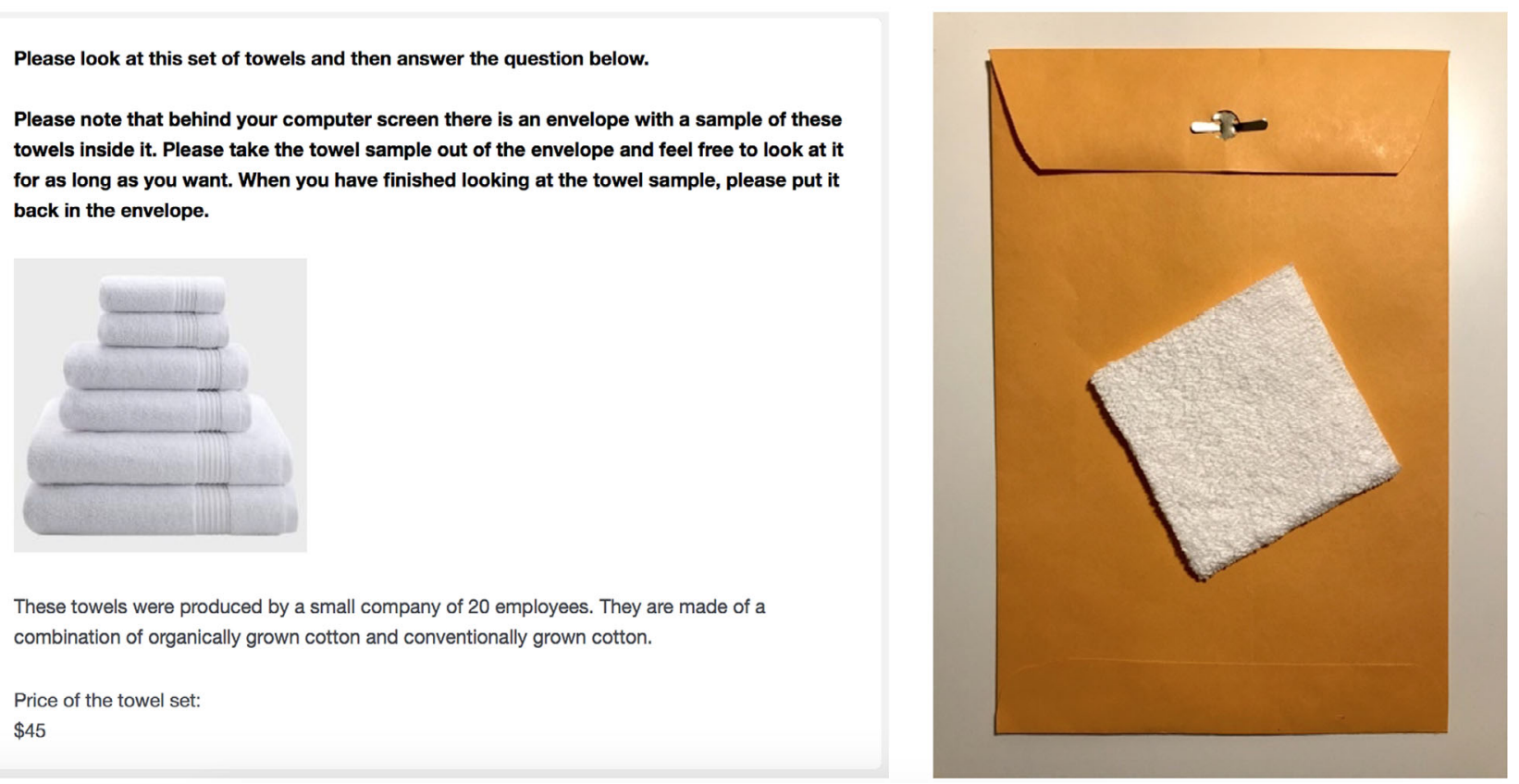

Figure 1. Stimuli for the small size condition of study 1 (in the large condition "20 employees" was substituted with "20000 employees"). On the left: stimuli shown on the screen; on the right: the towel sample that was given to the participants.

confirmed that organic cotton was perceived to be more natural $\left(M_{\text {organic }}=5.24, S D_{\text {organic }}=1.13\right.$ vs. $M_{\text {conventional }}=3.65, \quad S D_{\text {conventional }}=1.41 ; \quad t$ $(181)=13.20, p<.01)$.

\section{Results}

A 2 (firm size: small vs. large) $\times 2$ (salience of association: high vs. low) ANOVA, with the indicated percentage of organic cotton (i.e., perceived naturalness) as the dependent variable, showed a main effect of firm size on perceived naturalness $\left(M_{\text {small }}=44.07 \%, \quad S D_{\text {small }}=21.18 \% \quad\right.$ vs. $M_{\text {large }}=32.27 \%, S D_{\text {large }}=16.08 \% ; F(1,178)=17.82$, $p<.01, \eta^{2}=.09$ ), but not of salience of association $(p>.20)$, or their interaction $(p>.50)$.

Study 1 provides evidence for the association between firm size and perceived naturalness of products, even if participants interact with the same haptic stimuli across conditions, and whether attention is directed toward the association or not.

\section{Study 2}

In study 2, we used a liquid hand soap and asked for naturalness perceptions among other perceptions (i.e., not alone, resulting in possible demand effects). Additionally, we embedded firm size within many descriptors of the product to make it less salient, and we explored downstream consequences (purchase intention).

\section{Method}

Two hundred and eighty-seven undergraduate students completed this study in the behavioral laboratory of a mid-Western business school for course credit: Two were excluded for failing attention checks (details in MDA; final sample: $n=285$; $45.96 \%$ females, $M_{\text {age }}=20.13$ ).

Participants were shown a liquid hand soap advertisement (ad), which contained a product picture and description. We gave a long description of the product and embedded the firm size manipulation within this-we provided many product attributes such as "gentle formula," "energizes dull skin," "respects $\mathrm{pH}$ balance," and our description of firm size was just one more piece of information (Figure 2).

We measured participants' purchase intention using three items (7-point scales; adapted from Elder \& Krishna, 2012; Cronbach's $\alpha=.83$; details in MDA). As a measure of perceived naturalness, we used a constant sum scale as in study 1, with the two items to estimate being "natural" vs. "artificial" ingredients. Participants were told that "In general, soap can contain both natural ingredients 


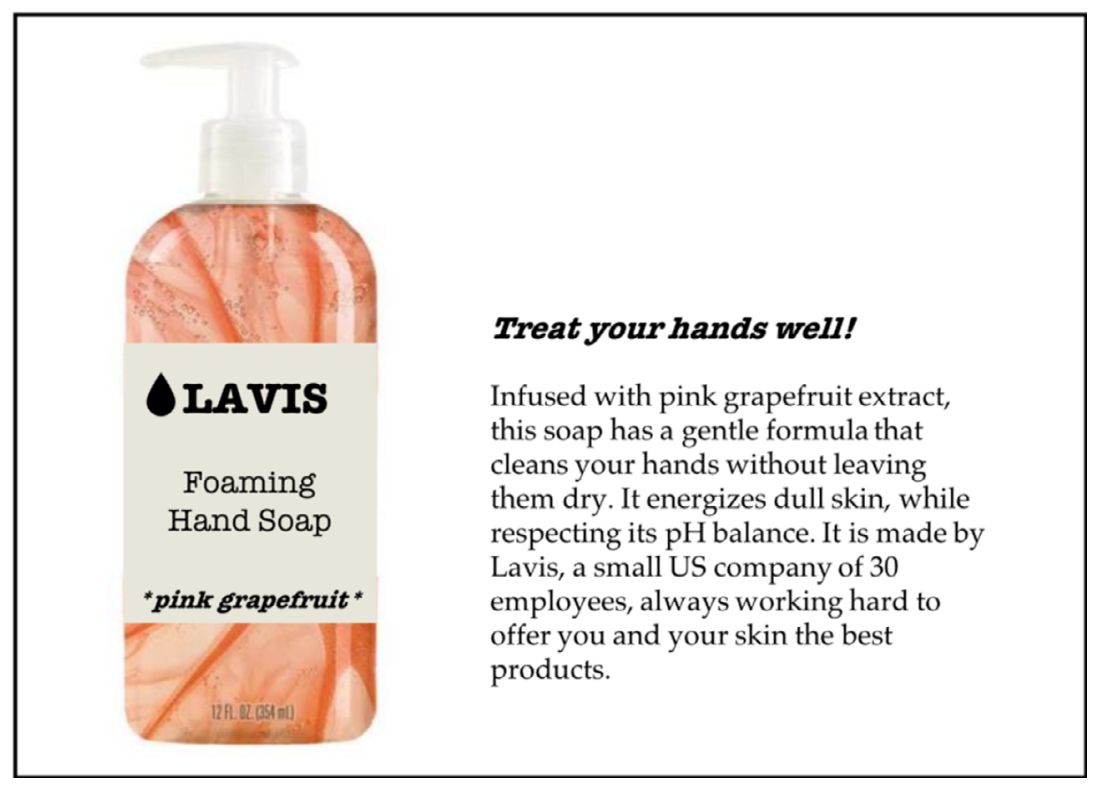

Figure 2. Stimuli for the small firm size condition of study 2 (for the large condition, we used "large US company of 30000 employees").

(such as vegetable oils) and artificial ingredients (such as synthetic fragrances)." Following purchase intention and perceived naturalness questions, participants answered two decoy questions (about package attractiveness and soap feel). These questions were added to make the naturalness variable stand out less and conceal the purpose of the experiment. As expected, firm size did not have an effect on either decoy variable ( $p s>.20)$.

A manipulation check after these main questions confirmed that participants perceived the firm as being smaller in the small (vs. large) condition $(p<.01)$.

To test for possible explanations for our effects, after two attention check questions, participants indicated the extent to which they agreed with five statements regarding firms: "large firm $=$ more artificial products"; "small firm = less processed products"; "large firm = less socially responsible"; "small firm = less profit-oriented"; "small firm $=$ more natural resources access" (exact statements provided in MDA).

\section{Results}

To test the effect of firm size $(0=$ small, $1=$ large $)$ on perceived naturalness and, consequently, on purchase intention, we used the PROCESS macro model 4 (Hayes, 2018; 95\% confidence level; 5,000 bootstrap samples). Results confirmed the significant effect of firm size on perceived naturalness $(\beta=-13.04, p<.01)$, and of perceived naturalness on purchase intention $(\beta=0.01, p<.01)$. The direct effect of firm size on purchase intention was not significant $(p>.20)$; nor was the total effect $(p>.50)$. However, the indirect effect of firm size on purchase intention, through perceived naturalness, was significant $(\beta=-0.17,95 \% \mathrm{CI}:-0.29$, -0.08 ). These results (Figure 3) suggest an indirectonly mediation (Zhao, Lynch, \& Chen, 2010): smaller firm size leads to higher perception of naturalness $\quad\left(M_{\text {small }}=53.96 \% ， S D_{\text {small }}=24.12 \% \quad\right.$ vs. $M_{\text {large }}=40.92 \%, S D_{\text {large }}=23.55 \%$ ), which in turn leads to a higher purchase intention.

The significant indirect effect, but nonsignificant total effect $\quad\left(M_{\text {small }}=2.96, \quad S D_{\text {small }}=1.11 \quad\right.$ vs. $\left.M_{\text {large }}=2.96, S D_{\text {large }}=1.20\right)$ suggests that firm size may impact purchase intention through multiple competing routes. While small firm size may signal increased naturalness, and consequently increase purchase intention, there may also be some strong negative perceptions related to firm size, which result in a null overall effect on purchase intention (MacKinnon, Krull, \& Lockwood, 2000; Rucker, Preacher, Tormala, \& Petty, 2011; Zhao et al., 2010). We test for purchase intention again in study 4.

\section{Beliefs regarding firm size}

The means for the five statements, which reflect beliefs regarding firm size, were not significantly different across the two firm size conditions 


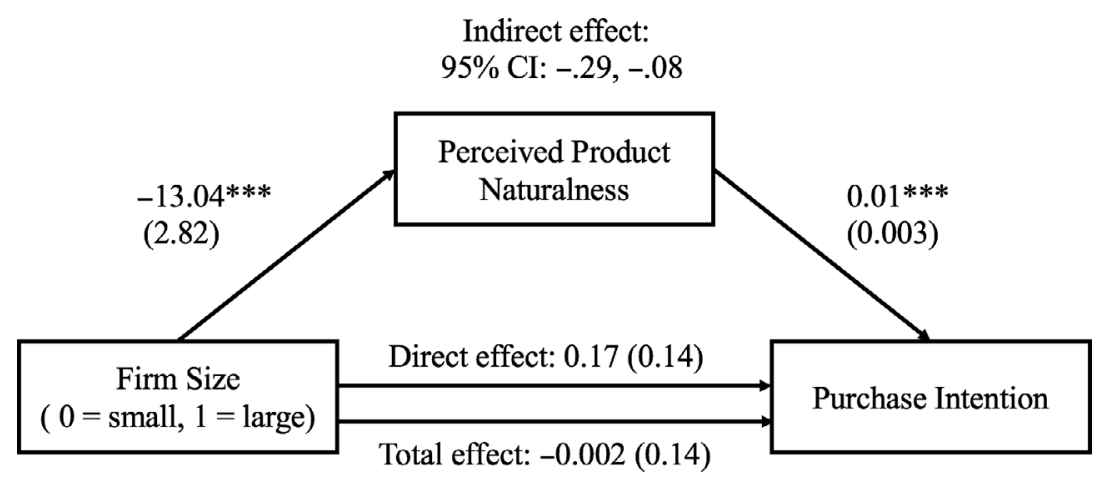

Figure 3. Results study 2: Indirect effect of firm size on purchase intention, through perceived product naturalness. Note.SEs are in parentheses. $* p<.10 ; * *<.05 ; * * p<.01$.

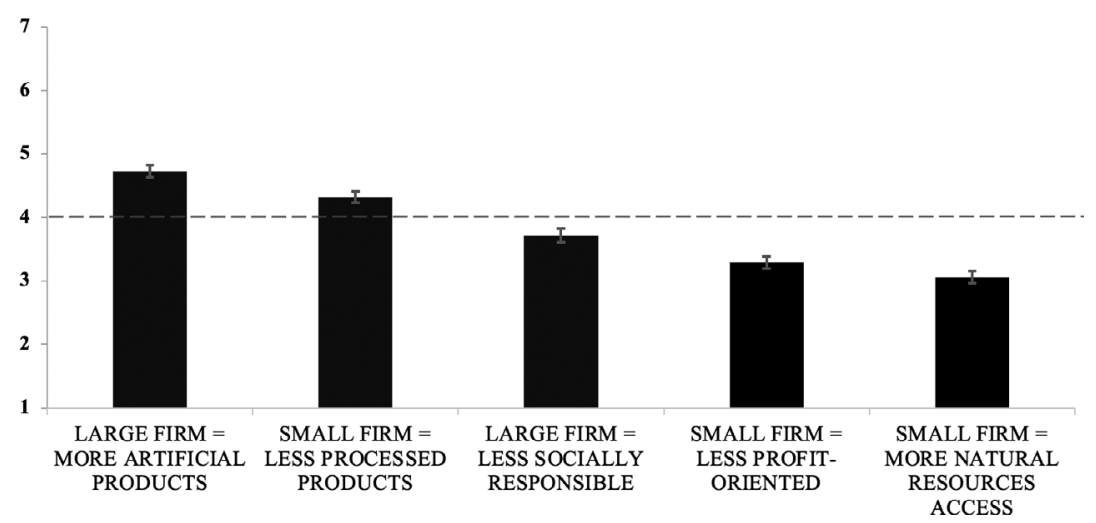

Figure 4. Results study 2: Mean agreement with statements regarding firm size. Note. The five statements were measured on: $1=$ strongly disagree, $7=$ strongly agree. Error bars $= \pm 1 S E$. The dashed line represents the scale midpoint (i.e., value 4 ).

$(p s>.05)$ and are hence pooled across conditions (Figure 4). All five means are significantly different from the midpoint (i.e., value $4 ; p s<.01$ ) and from each other $(p s<.05)$, with beliefs related to sizenaturalness association (i.e., "large firm = more artificial products," and the less direct "small firm $=$ less processed products") being the only ones significantly higher than the midpoint: that is, participants believe quite strongly that products of larger firms are more likely to contain artificial ingredients and be more processed.

We estimated five moderated mediation models which include the five beliefs (Figure 4) as moderators into the model presented in Figure 3. The only belief that (marginally) moderated the effect of firm size on naturalness was the "large firm = more artificial products" belief; this was also the belief of interest since it pertains to a conscious association between firm size and naturalness (method adapted from Raghubir \& Valenzuela, 2006).

The MDA reports details for all five moderated mediation models, but the results for "large firm $=$ more artificial products" belief as moderator are also provided in Table 1 here. Importantly, the interaction of firm size and the belief is marginally significant $(p<.10)$, implying a moderation of the effect of firm size on perceived naturalness.

To explore this interaction further, we looked at conditional effects of firm size, at one standard deviation below and above the mean of the moderator ("large firm = more artificial products" belief). Table 1B shows a larger conditional effect of firm size on perceived naturalness at a high versus low value of the belief $\left(B_{M-1 S D}=-8.48, B_{M+1 S D}=-18.33\right)$. This suggests that a stronger conscious belief that smaller firms make more natural products than larger firms results in a stronger effect of firm size on perceived naturalness; and consequently a stronger indirect effect on purchase intention (Index of moderated mediation marginally significant: $-0.04 ; 90 \%$ CI: $-0.08,-0.003$; CI was obtained repeating the bootstrap analysis, with confidence level set to $90 \%$ ). The direct effect of firm size on purchase intention is not significantly impacted by the strength of the belief. 
Table 1

Study 2 Moderated Mediation Model (Hayes Model 8: 5,000 Draws, 95\% CI)

(A) Model output

\begin{tabular}{|c|c|c|c|c|}
\hline Independent variable & $\begin{array}{c}\text { DV: perceived naturalness } \\
B(S E)\end{array}$ & $p$ & $\begin{array}{l}\text { DV: purchase intention } \\
\qquad B(S E)\end{array}$ & $p$ \\
\hline Constant & $54.24(1.97)$ & .000 & $2.28(0.18)$ & .000 \\
\hline Firm Size $(0=$ small, $1=$ large $)$ & $-13.40(2.77)$ & .000 & $0.16(0.14)$ & .26 \\
\hline Perceived Naturalness & - & & $\mathbf{0 . 0 1}(0.003)$ & .000 \\
\hline "Large firm = more artificial products" belief & $4.44(1.31)$ & .001 & $-0.004(0.06)$ & .96 \\
\hline Firm Size * "Large firm $=$ more artificial products" belief & $-3.14(1.78)$ & .079 & $0.11(0.09)$ & .20 \\
\hline
\end{tabular}

(B) Conditional effects of Firm size at different values of the moderator ("Large firm = more artificial products" belief; mean-centered)

\begin{tabular}{|c|c|c|c|c|c|c|}
\hline \multirow[b]{2}{*}{ Moderator value } & \multicolumn{2}{|c|}{ Effect on perceived naturalness } & \multicolumn{2}{|c|}{$\begin{array}{l}\text { Indirect effect on purchase } \\
\text { intention through perceived } \\
\text { naturalness }\end{array}$} & \multicolumn{2}{|c|}{$\begin{array}{l}\text { Direct effect on purchase } \\
\text { intention }\end{array}$} \\
\hline & $B$ & $95 \% \mathrm{CI}$ & $B$ & $95 \% \mathrm{CI}$ & $B$ & $95 \% \mathrm{CI}$ \\
\hline$M-1 S D=-1.57$ & -8.48 & $-16.21,-0.75$ & -0.11 & $-0.23,-0.01$ & -0.01 & $-0.39,0.36$ \\
\hline$M=0$ & -13.40 & $-18.87,-7.94$ & -0.17 & $-0.29,-0.07$ & 0.16 & $-0.11,0.43$ \\
\hline$M+1 S D=1.57$ & -18.33 & $-26.08,-10.57$ & -0.23 & $-0.40,-0.10$ & 0.33 & $-0.06,0.71$ \\
\hline
\end{tabular}

Note. Coefficients significantly different from zero are in bold.

Study 2 provides evidence for an indirect-only mediation effect of firm size on purchase intention, through perceived naturalness. Furthermore, people may hold the belief regarding firm size and product naturalness consciously, and the firm size-naturalness association is stronger when this conscious belief is stronger.

In the next study, we explore whether the sizenaturalness belief is also held implicitly.

\section{Study 3}

In study 3, we used the implicit association test (IAT) procedure (Greenwald, McGhee, \& Schwartz, 1998) to investigate whether people hold the "small firm = natural product" ("big firm = artificial product") $^{\prime \prime}$ association implicitly. This procedure consists of binary categorization tasks: The categorization is expected to be faster when the two categories related to the same response key are congruent versus incongruent.

\section{Method}

Two hundred and ninety undergraduate students completed the study in the laboratory of a
mid-Western business school for course credit: Five were excluded by the IAT algorithm (final sample: $n=285 ; 50.90 \%$ females, $M_{\text {age }}=20.12$ ).

We conducted a pretest (details in MDA) to select four words to use for "natural product" (organic, herbal, raw, unprocessed) and "artificial product" (synthetic, plastic, fabricated, processed) categories. We selected four words used in everyday language for the "small company" (little, tiny, micro, smaller) and "big company" (huge, large, giant, bigger) categories.

Participants were presented with seven blocks: five practice and two main blocks (details in MDA). In the main "congruent" block, participants assigned words on the screen to the "natural product or small company," or the "artificial product or big company" categories. In the main "incongruent" block, the categories were paired in the opposite way (i.e., "artificial product or small company" and "natural product or big company").

\section{Results}

The overall IAT effect was significant $\left(M_{\text {Dscore }}=0.31, S D=0.45, t(284)=11.64, p<.01\right.$, $\left.95 \% \mathrm{CI}_{\text {D-Score }}[0.26,0.37], d=0.69\right)$; and response times were shorter in the congruent versus 
incongruent block $\left(M_{\text {congruent }}=898.54 \mathrm{~ms} \quad\right.$ vs. $M_{\text {incongruent }}=1,030.12 \mathrm{~ms}$ ). These results provide evidence for the "small firm = natural product" ("big firm = artificial product") implicit association. Another IAT study (details in MDA) showed an implicit association of the broad concepts of size and naturalness: "small = natural", "big = artificial".

\section{Study 4}

When this study was being planned (March 2020), COVID-19 spread around the world and popular press suggested that in this situation of high anxiety, consumers would have higher trust in large firms and prefer to buy from them (e.g., https:/ / www.thegazette.com/subject/news/nation-andworld/as-coronavirus-disrupts-daily-life-consumersseek-comfort-old-brands-20200429; https://www.be veragedaily.com/Article/2020/05/06/Back-to-thebig-brands-Coronavirus-shapes-beverage-consumertrends). But, could "small size" still cue "naturalness" and impact purchase intentions?

In line with the context, we used hand cream as the product and told participants "You have probably been using a lot of soap and disinfectant over these past weeks, and you need to keep your hands nourished. On the next page, you will be shown an ad for a hand cream." Additionally, we cued firm size in an ecologically valid manner, using the number of stores on a store locator map. Furthermore, to explore whether the firm size effect is driven more by the small-natural or the large-artificial association, we included a control condition with no mention of firm size.

\section{Method}

Two hundred and fifty-two undergraduate female students of a mid-Western business school completed this study (online) for course credit. We use only females since the product and ad shown are more relevant for them. Three students were removed for not passing an attention check (details in MDA; final sample: $n=249 ; M_{\text {age }}=20.00$ ).

Participants saw a hand cream ad which contained a product picture, price, and description. The ad either had no mention of the number of stores (control condition), or mentioned three stores (small condition), or three hundred stores (large condition), with stores shown on a U.S. store locator map (Figure 5). In both the small and large condition, one store was located in the state where the business school is located.

We measured participants' purchase intention using three items (details in MDA; Cronbach's $\alpha=0.83$ ) and perceived naturalness using a constant sum scale, as in study 2. Participants also answered two decoy questions as in study 2, which yield no difference across the three conditions (ps > .50).

A manipulation check showed that perceived size was significantly different when comparing all three conditions to one another ( $p$ s $<.05)$, and smallest in the small condition, and largest in the large condition, with control in between.

We asked participants to evaluate how surprising, novel, and vivid the information was in the ad they saw, to make sure the firm size conditions did not differ on these dimensions-they did not (ps > .10).

Next, we measured participants' expertise with hand creams, and expertise with natural/organic products (details in MDA) as potential moderators. The two expertise measures did not vary across firm size conditions ( $p$ s $>.50)$.

\section{Results}

We estimate model 4 of the PROCESS macro (Hayes, 2018; 95\% confidence level; 5,000 bootstrap samples), with firm size as the independent variable, purchase intention as the dependent variable, and perceived naturalness as the mediator. The baseline for firm size is the control condition, and two dummy-coded parameters reflect the small and large condition (Hayes \& Preacher, 2014).

We find (Table 2) that the small firm (vs. control) has higher perceived naturalness $(\beta=9.22, p<.01)$, while the effect of the large condition is not significantly different from control. This suggests that the firm size effect on perceived naturalness is driven more by the small-natural association. The results also confirm the significant positive effect of perceived naturalness on purchase intention $(\beta=0.01$, $p<.01)$.

The relative indirect effect of small firm size (vs. control) on purchase intention, through perceived naturalness, was significant, and positive $(\beta=0.11$, 95\% CI: 0.02, 0.24): that is, small firm size had higher perceived naturalness which then increased purchase intention. The direct and total effects of firm size on purchase intention were not significant for the large condition (vs. control; $p$ s $>.50$ ), but were significant and negative for the small condition 


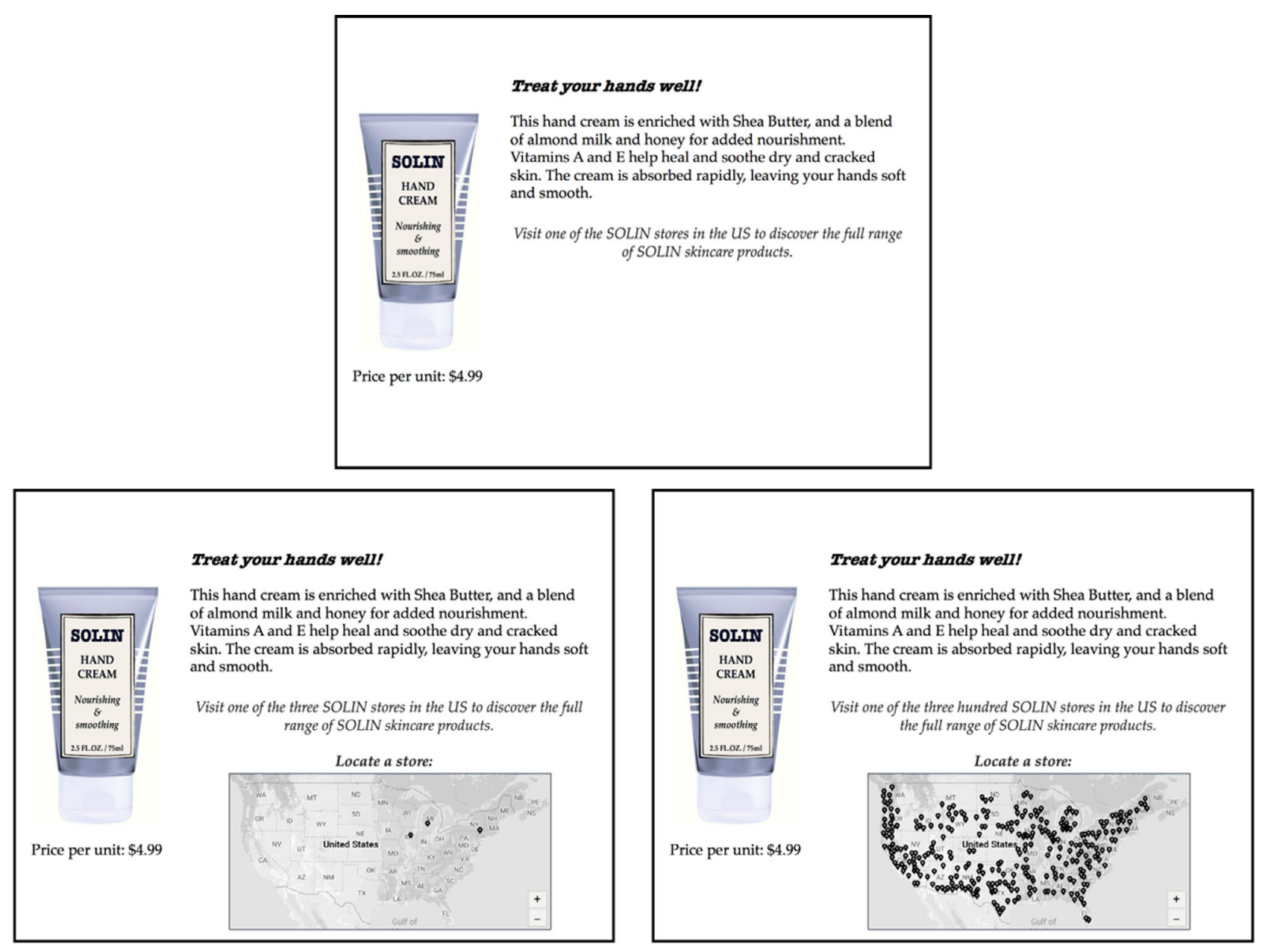

Figure 5. Study 4 stimuli-firm size: control (top); small (bottom left); large (bottom right).

Table 2

Study 4 Mediation Model (Hayes Model 4: 5,000 Draws, 95\% CI)

\begin{tabular}{|c|c|c|c|c|}
\hline \multirow[b]{2}{*}{ Independent variable } & \multicolumn{2}{|c|}{$\begin{array}{l}\text { DV: perceived } \\
\text { naturalness }\end{array}$} & \multicolumn{2}{|c|}{$\begin{array}{l}\text { DV: purchase } \\
\text { intention }\end{array}$} \\
\hline & $B(S E)$ & $p$ & $B(S E)$ & $p$ \\
\hline Constant & $56.22(2.36)$ & .000 & $2.32(0.23)$ & .000 \\
\hline SMALL Firm size $\mathrm{e}^{\mathrm{a}}$ & $9.22(3.43)$ & .008 & $-0.55(0.19)$ & .004 \\
\hline LARGE Firm size $^{\mathrm{a}}$ & $1.65(3.22)$ & .61 & $-0.04(0.18)$ & .82 \\
\hline Perceived Naturalness & - & & $0.01(0.004)$ & .001 \\
\hline
\end{tabular}

Note. Coefficients significantly different from zero are in bold.

${ }^{\mathrm{a}}$ Control condition is the baseline.

(vs. control; $\beta_{\text {direct }}=-0.55, p<.01 ; \beta_{\text {total }}=-0.44$, $p<.05$; raw purchase intention means: $M_{\text {small }}=2.58, \quad S D_{\text {small }}=1.28, \quad M_{\text {control }}=3.02$, $S D_{\text {control }}=1.15 ; M_{\text {large }}=3.00, S D_{\text {large }}=1.15$ ).

Repeating the mediation analysis with the small firm size condition as baseline, confirmed that perceived naturalness was significantly lower in the large (vs. small) condition $(\beta=-7.57, p<.05)$ and showed a significant relative indirect effect on purchase intention $(\beta=-0.09,95 \% \mathrm{CI}:-0.21,-0.01)$. The mediation results for the relative effects of large (vs. small) firm size are summarized in Figure 6, and point to a competing mediation (Zhao et al., 2010), suggesting, as in study 2, that there exist competing underlying effects of firm size on purchase intention that require further research.

\section{Expertise}

Expertise with natural/organic products had a marginal $(p=.06)$ conditional interaction with small (vs. control) firm size effect on perceived naturalness (details in MDA). [Expertise with hand creams was not a significant moderator]. Spotlight analysis showed that only average and high levels of 


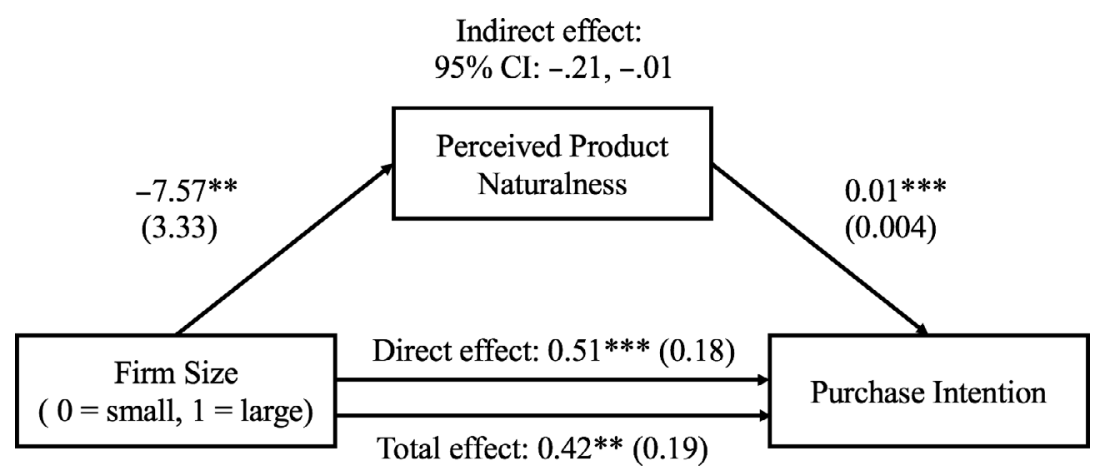

Figure 6. Results study 4: Relative indirect effect of large (vs. small) firm size on purchase intention, through perceived product naturalness. Note.SEs are in parentheses. ${ }^{*} p<.10 ;{ }^{* *} p<.05 ;{ }^{* * *} p<.01$.

expertise resulted in a significant small (vs. control) firm size effect on naturalness, suggesting that consumers with expertise on naturalness may be more prone to make the "smaller firm = more natural products" association. However, while showing the same trend, the interaction of expertise with the small vs. large firm size effect was not significant $(p>.10)$.

Our results show that even in a situation where large firms are favored, the small firm size holds a naturalness association and can help with purchase intention. The firm size effect seems more driven by the "small-natural" association rather than the "large-artificial" association. However, this result needs to be explored further to understand what exactly the control condition conveys about the product and the firm.

\section{General Discussion}

Our results indicate that consumers may rely on firm size as a cue when evaluating product naturalness, such that there is a "smaller firm = more natural product" intuition. The intuition seems driven more by small firms being associated with natural, than by large firms with artificial. Furthermore, we find that the increase in perceived naturalness translates to an increase in purchase intention. However, while we find a positive indirect effect through increased perceived naturalness, we do not find an overall effect of small firm size on purchase intention-suggesting the existence of competing mediators, operating in the opposite direction. Preliminary evidence from an online posttest indicates that in contexts of high uncertainty, such as the 2020 pandemic, consumers may expect it to be more difficult to shop from a smaller firm. Further thought and testing is needed on competing underlying processes activated by the firm size cue.

Our findings on firm size are particularly relevant given a climate of frequent mergers and acquisitions, with many larger firms buying small "health food" or "organic product" firms. For example, Coca Cola acquired Honest Tea (organic bottled tea), Colgate-Palmolive purchased Tom's of Maine (natural personal care products), Clorox owns Burt's Bees (natural skincare products), and Kellogg's purchased Kashi (organic food). Anecdotal evidence from Twitter suggests that these mergers make consumers question the continuing naturalness of products (e.g., "Clorox owns Burt's Bees. Colgate owns Tom's of Maine. Kind of losing faith in all the "natural" products out there."), inviting more research on mergers.

At a more conceptual level, we show the importance of understanding how firm cues affect product perception, a topic with little research. While firms' overall ability and corporate social responsibility as cues for product goodness have been studied (Bhattacharya \& Sen, 2004; Brown \& Dacin, 1997; Sen \& Bhattacharya, 2001), there is much more work that can link various firm cues (e.g., gender-ratio of the workforce, whether the workforce is domestic or international, political affiliation of the CEO) to perceptions of various product attributes (e.g., level of quality control, how environmental the product is, technical sophistication, customer service).

Future research could also test for ways in which firms can signal their size to consumers: for example, through brand names (e.g., having "small," "little," "tiny," in the name), or through "stories about the firm" on their packaging; and could investigate how the "size-naturalness" association interacts with different dimensions of brand equity, such as firm expertise and trust. 
Finally, more research can be done to disentangle the conscious and unconscious nature of the "small = natural" association, and explore other contexts in which this association may have a role. We hope that our research spurs additional work in all these areas.

\section{References}

Bhattacharya, C. B., \& Sen, S. (2004). Doing better at doing good: When, why, and how consumers respond to corporate social initiatives. California Management Review, 47, 9-24.

Broniarczyk, S. M., \& Alba, J. W. (1994). The role of consumers' intuitions in inference making. Journal of Consumer Research, 21, 393-407.

Brown, T. J., \& Dacin, P. A. (1997). The company and the product: Corporate associations and consumer product responses. The Journal of Marketing, 61, 68-84.

Elder, R., \& Krishna, A. (2012). The visual depiction effect: Inducing embodied mental simulation that evokes motor responses. Journal of Consumer Research, $38,988-1003$.

Greenwald, A. G., McGhee, D. E., \& Schwartz, J. L. (1998). Measuring individual differences in implicit cognition: The implicit association test. Journal of Personality and Social Psychology, 74, 1464.

Haws, K. L., Reczek, R. W., \& Sample, K. L. (2016). Healthy diets make empty wallets: The healthy $=$ expensive intuition. Journal of Consumer Research, 43, 9921007.

Hayes, A. F. (2018). Introduction to mediation, moderation, and conditional process analysis: A regression-based approach (2nd ed.) The Guilford Press.

Hayes, A. F., \& Preacher, K. J. (2014). Statistical mediation analysis with a multicategorical independent variable. British Journal of Mathematical and Statistical Psychology, 67, 451-470.

Labbe, D., Pineau, N., \& Martin, N. (2013). Food expected naturalness: Impact of visual, tactile and auditory packaging material properties and role of perceptual interactions. Food Quality and Preference, 27, 170-178.

Lakoff, G., \& Johnson, M. (1980). Conceptual metaphor in everyday language. The Journal of Philosophy, 77, 453486.

MacKinnon, D. P., Krull, J. L., \& Lockwood, C. M. (2000). Equivalence of the mediation, confounding and suppression effect. Prevention Science, 1, 173-181.
Marckhgott, E., \& Kamleitner, B. (2019). Matte matters: When matte packaging increases perceptions of food naturalness. Marketing Letters, 30, 167-178.

Raghubir, P., \& Valenzuela, A. (2006). Center-of-inattention: Position biases in decision-making. Organizational Behavior and Human Decision Processes, 99, 66-80.

Raghunathan, R., Naylor, R. W., \& Hoyer, W. D. (2006). The unhealthy= tasty intuition and its effects on taste inferences, enjoyment, and choice of food products. Journal of Marketing, 70, 170-184.

Rozin, P. (2005). The meaning of "natural" process more important than content. Psychological Science, 16, 652658.

Rozin, P., \& Nemeroff, C. (1990). The laws of sympathetic magic: A psychological analysis of similarity and contagion. In J. W. Stigler, R. A. Shweder, \& G. Herdt (Eds.), Cultural psychology: Essays on comparative human development (pp. 205-232). Cambridge University Press.

Rozin, P., Spranca, M., Krieger, Z., Neuhaus, R., Surillo, D., Swerdlin, A., \& Wood, K. (2004). Preference for natural: Instrumental and ideational/moral motivations, and the contrast between foods and medicines. Appetite, 43, 147-154.

Rucker, D. D., Preacher, K. J., Tormala, Z. L., \& Petty, R. E. (2011). Mediation analysis in social psychology: Current practices and new recommendations. Social and Personality Psychology Compass, 5, 359-371.

Sen, S., \& Bhattacharya, C. B. (2001). Does doing good always lead to doing better? Consumer reactions to corporate social responsibility. Journal of Marketing Research, 38, 225-243.

Smith, R. K., Newman, G. E., \& Dhar, R. (2015). Closer to the creator: Temporal contagion explains the preference for earlier serial numbers. Journal of Consumer Research, 42.

Swamidass, P. M., \& Kotha, S. (1998). Explaining manufacturing technology use, firm size and performance using a multidimensional view of technology1. Journal of Operations Management, 17, 23-37.

Zhao, X., Lynch, J. G. Jr, \& Chen, Q. (2010). Reconsidering Baron and Kenny: Myths and truths about mediation analysis. Journal of Consumer Research, 37, 197-206.

\section{Supporting Information}

Additional supporting information may be found in the online version of this article at the publisher's website:

Appendix S1. Methodological Details Appendix. 